Boise State University

ScholarWorks

Psychological Sciences Faculty Publications and

Presentations

Department of Psychological Science

6-1-2007

\title{
Is Self-Esteem the Primary Predictor of Disordered Eating?
}

Maureen E. Shea

Boise State University

Mary Pritchard

Boise State University

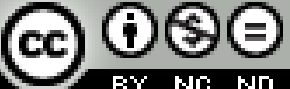

This is an author-produced, peer-reviewed version of this article. (C) 2009, Elsevier. Licensed under the Creative Commons AttributionNonCommercial-NoDerivatives 4.0 International License (https://creativecommons.org/licenses/by-nc-nd/4.0/). The final, definitive version of this document can be found online at Personality and Individual Differences, doi: 10.1016/j.paid.2006.10.026 


\title{
Is Self-Esteem the Primary Predictor of Disordered Eating?
}

\author{
Maureen E. Shea \\ Mary Pritchard \\ Boise State University
}

\begin{abstract}
This study examined whether self-esteem is the primary predictor of disordered eating. A survey measured levels of self-esteem and a variety of other health behaviors in 196 male and 263 female undergraduate students. We conducted stepwise regressions to determine which of several variables (self-esteem, high stress, poor coping skills, maladaptive perfectionism, gender) best predicted disordered eating. The results indicated that self-esteem was the secondary predictor for bulimia, drive for thinness, and body dissatisfaction. Future research should further investigate how self-esteem interacts with other predictor variables to better determine the relationship between self-esteem and disordered eating.
\end{abstract}

Eating disorders are becoming increasingly common among American college students today. Precise estimates of incidence and prevalence vary, but tend to range from about 3\% to 10\% for females 15-29 years of age (Polivy \& Herman, 2002) and about 2.4\% for males (Espina, Ortego, Ochoa, Aleman, \& Juaniz, 2002). Although a majority of the research in the field of eating disorders focuses on women, recently attention to these topics in males has been on the rise (Pope, Phillips, \& Olivardia, 2002). In fact, it has been estimated that $10 \%$ of the people with anorexia and bulimia nervosa are men (Weltzin et al., 2005).

It is undisputed that low self-esteem contributes to disordered eating. For example, Button, Loan, Davies, and Sonuga-Barke (1997) found that girls who displayed eating disordered behaviors also reported lower self-esteem. In addition, girls with higher levels of disordered eating behaviors displayed higher levels of overall dissatisfaction with themselves, their appearance, and their family relationships. Furthermore, it has been shown that low selfesteem is positively correlated to disordered eating in college students (Granillo, Jones-Rodriguez, \& Carvajal, 2005) and a decrease in self-esteem contributes to poorer body image (Abell \& Richards, 1996; Gleason, Alexander, \& Somers, 2000) and bulimic symptoms (Vohs, Bardone, Joiner, Abramson, \& Heatherton, 1999). Certainly a number of other factors such as stress, perfectionism, coping styles and gender also influence disordered eating, but to what degree is unknown. Below, we will discuss how self-esteem and various other factors impact eating pathologies.

\section{Self-esteem}

In a longitudinal study of women conducted by Gilbert and Meyer (2005), results revealed that low self-esteem predicted an increase in body dissatisfaction and that negative evaluation fears predicted an increase in bulimic attitudes and depression. This result supports the idea that with low self-esteem as a primary catalyst, followed by dissatisfaction of one's body, bulimic symptoms and/or depression can follow. Perhaps, these fears of negative evaluation stem from societal and cultural pressures to be thin and that value thin as the ideal (Finstad, 2003). Finstad found that this internalization and personal investment in the thin-ideal, coupled with disordered eating scores, was predicted by lower self-esteem as well as greater importance placed on appearance as a source of selfesteem in adolescent females. Further research is consistent with Finstad's findings. A study conducted in Denmark indicated that women suffering from an eating disorder had lower self-esteem, used more inefficient coping methods, and were exposed to more stress than those who were not struggling with disordered eating (Blaase \& Elklit, 2001).

In 2005, a number of researchers examined body image dissatisfaction in obese men and women seeking surgery to solve the problem. In men, $56 \%$ of the variance was accounted for by binge eating and self-esteem, whereas it was $33 \%$ of the variance in women (Grilo, Masheb, Brody, Burke-Martindale, \& Rothschild, 2005). Their findings indicate a need for more understanding regarding self-esteem and its relationship to body image dissatisfaction in those who are obese. Shapiro (1999) completed a second study regarding self-esteem and those who are overweight. 
This research evaluated the effects of threats to self-esteem on eating in overweight women. The results showed that women with low self-esteem responded differently in their restraint, disinhibition, and susceptibility to hunger from those with high self-esteem. Shapiro acknowledged the fact that more research was needed to further understand the role of self-esteem on eating habits.

\section{Stress}

Other studies have looked at the relationship between health and stress. Rector and Roger (1997) specifically examined the interaction between self-esteem and stress in female undergraduates. In their experiment, the high selfesteem group showed less stress responsivity, better performance on the Stroop task and lower heart rate during a social performance task. This study suggests that self-esteem has inherent buffering effects against stress. The research of Sassaroli and Ruggiero (2005) also supports this conclusion. Sassaroli and Ruggiero attempted to determine the role of stress in association to low self-esteem, perfectionism, worry and eating disorders in female adolescents. They found that while in a stressful situation, these factors were associated. Whereas low self-esteem and worry were associated only during the stressful situation, perfectionism was associated in both stressful and non-stressful situations. Thus, stress may elicit poor health behaviors.

Specifically, according to Bailer and Kaye (2003), the stress hormones in those suffering from anorexia and bulimia have been observed to be consistently elevated. The primary stress hormone cortisol, helps inhibit neuropeptide Y which functions as an appetite stimulant. This could be a biological connection to eating disordered behavior and stress. Although they do acknowledge that more research needs to be done to see if irregularities in stress hormone levels are a cause or a result of eating disorders, the fact that stress plays a role is apparent.

\section{Perfectionism}

Self-esteem's contribution to perfectionism and therefore, perfectionism's effects on eating disorders has also been reviewed. It appears that perfectionism minimally presents an underlying vulnerability. A study conducted by Eckerd (2005) confirmed previous findings that perfectionism is linked with disordered eating in women. A relationship between disordered eating and perfectionism was present. In addition, in a study examining anorexia nervosa in women, Halmi et al. (2000) determined that those suffering from anorexia had significantly higher scores on perfectionism scales than did their healthy counterparts.

In another study, aiming to determine in what way perfectionism was related to eating disorders among other psychopathologies, it was found that an increase in concern over mistakes was associated with anorexia and bulimia but not other disorders. This suggests that perfectionism may be more predictive of disordered eating than other pathologies and may work in concert with low self-esteem in women (Bulik et al., 2003).

\section{Gender}

Gender is another salient feature of disordered eating. Kiefer, Rathmanner and Kunze (2005) reported that women suffer more eating disorders, diet more than men and practice restrained eating more than men do. Although rates of obesity are roughly equal between the two groups, women suffer more problems as a result of their eating behaviors. Anderson and Bulik (2004) reported much of the same in their study, stating that in women greater importance was placed on weight, shape and drive for thinness. In 2002, Furnham, Badmin and Sneade found that males were as likely to want to lose weight as gain it and that only a few females expressed a desire to weigh more. In addition, self-esteem did not affect body image dissatisfaction in males as it did in females.

\section{Present Study}

Although much research has been conducted in which self-esteem is a contributing factor to other health ailments, minimal research has been completed in which self-esteem is investigated as the primary culprit or the most powerful predictor. Current research frequently hypothesizes that self-esteem is $a$ predictor (at least one of many) in major disorders but it has rarely, if ever, been treated as the primary predicting factor or the salient feature of disordered eating.

We hypothesize that low self-esteem is fundamentally detrimental to general health and that it will be the primary predictor (among other predictors such as high stress, poor coping skills, maladaptive perfectionism, and gender) for disordered eating. 


\section{Participants}

\section{Method}

There were 460 participants, ranging in age from 16 to $56(M=23.15, S D=7.04)$. They were selected through the Psychology Department volunteer subject pool consisting of 101 students at a large state university in the Pacific Northwest. Students were not screened for eating disorders prior to study participation. There were 196 male participants and 263 female participants; one participant did not respond to the gender item. Following completion of the survey, the students were debriefed and given credit that counted towards their course work. The Institutional Review Board approved all procedures before the study began.

\section{Disordered eating and body dissatisfaction}

\section{Measures}

Disordered eating behaviors were assessed with the Eating Disorder Inventory (Garner, Olmstead, \& Polivy, 1983), which asked about students' eating habits (e.g., I eat when I am upset) as well as how they feel about their bodies (e.g., I think that my stomach is too big). Responses were rated on a 5-point scale ( $0=$ never/rarely, $4=$ always), with higher scores indicating more disordered eating and body dissatisfaction ( $\alpha$ s ranged from .85 to .90). Consistent with previous research (e.g., Suldo \& Sandberg, 2000), we utilized the three subscales connected most with disordered eating: bulimia (e.g., I eat when I am upset), drive for thinness (e.g., I think about dieting), and body dissatisfaction (e.g., I think that my stomach is too big).

\section{Self-esteem}

Levels of self esteem were measured using the Rosenberg Self Esteem Scale, which has been shown to be both valid and reliable (Rosenberg, 1989). This scale uses a variety of questions assessing personal feelings about oneself as well as positive and negative emotions (e.g., I feel I have a number of good qualities). Responses were measured on a 4-point scale ( 1 =strongly agree, $4=$ strongly disagree) and demonstrated adequate reliability in this study ( $\alpha=.87)$.

\section{Perfectionism}

Perfectionism was assessed with the Perfectionism Scale Self Test (Vredevelt, Newman, Beverly \& Minirth, 1992; e.g., I should be upset if I make a mistake). Responses were rated on a 4-point scale $(0=$ never, $3=$ often) and summed to create a scale score $(\alpha=.82)$.

\section{Stress}

We assessed 37 stressful events specifically oriented to college students' lives (e.g., “struggling to meet your own academic standards”) using the Inventory of College Student Recent Life Experiences (Kohn, Lafreniere, \& Gurevhich, 1990). Students were asked to rate to what extent such events have been a part of their lives in the past month on a 4 - point scale (1=not at all, $4=$ very much). This scale has been shown to be reliable and valid and demonstrated good reliability in this study $(\alpha=.87)$.

\section{Coping}

Students were asked to respond to a list of 66 coping strategies from the Ways of Coping Scale (Folkman, Lazarus, Dunkel-Schetter, DeLongis, \& Gruen, 1986; e.g., I tried to analyze the problem in order to understand it better). Responses were rated on a 4-point scale $(0=$ not used, $3=a$ great deal) and demonstrated good reliability in this data $(\alpha=.92)$. The Ways of Coping Scale measures eight types of coping: 1) Confrontive Coping describes aggressive efforts to alter the situation, 2) Distancing describes cognitive efforts to detach oneself and to minimize the significance of the situation, 3) Self-Controlling describes efforts to regulate one's feelings and actions, 4) Seeking Social Support describes efforts to seek informational support, tangible support, and emotional support, 5) Accepting Responsibility acknowledges one's own role in the problem with an emphasis on trying to put things right, 6) Escape-Avoidance describes wishful thinking and behavioral efforts to escape or avoid the problem, 7) Planful Problem Solving describes problem-focused efforts to alter the situation, and 8) Positive Reappraisal describes efforts to create positive meaning by focusing on personal growth or religion/prayer. 


\section{Procedure}

In conducting this survey participants were tested in groups in a classroom situation. Each participant received a survey and a brief set of instructions. They were given approximately 50 min to complete the survey and most used nearly all of the available time.

\section{Results}

Before examining the extent to which self-esteem predicts disordered eating, we wanted to determine if there were gender differences in any of our variables as gender was one of the factors known to influence disordered eating. As displayed in Table 1, women were more likely to display drive for thinness, bulimia, and body dissatisfaction than were men. Women were also more likely to utilize social support and escape as forms of coping. Finally, women reported higher levels of stress and self esteem. Men, on the other hand, reported utilizing more distancing and problem solving as coping strategies.

To assess whether our participants scores on the dependent variables were similar to those of other students, we researched the original norms for the EDI. When compared to gender matched norms, the women in our study had more body dissatisfaction $(M=14.06)$ than the female comparison group $(M=10.2)$ that the EDI was tested on by the survey developers; the males in our study $(M=6.58)$ also displayed more body dissatisfaction than the male comparison group $(M=3.9)$ in the original EDI study (Garner et al., 1983). This is not surprising given that body dissatisfaction has risen since the 1980s. Similarly, the women in our study $(M=2.46)$ displayed slightly higher means than those originally reported by Garner et al. $(M=2.0)$, as did the men $(M=1.18)$ in our study compared to the original male control group $(M=1.0)$. Finally, the women in our study reported higher mean drive for thinness ( $M=6.72)$ than the original group $(M=5.0)$, as did the men in our group $(M=2.39)$ compared to the original controls $(M=1.6)$.

The purpose of this study was to ascertain to what extent self-esteem predicts disordered eating. To this end, we conducted stepwise regressions, regressing self-esteem, stress, coping skills, maladaptive perfectionism, and gender on the dependent variables. Data from missing variables was excluded from all analyses. Results are presented in the paragraphs below and in accompanying tables.

To assess whether self-esteem was the primary predictor for disordered eating, we regressed all of the predictor variables on bulimia, drive for thinness and body dissatisfaction. As presented in Table 2, escape coping was the primary predictor for bulimia, followed by self-esteem, stress and gender (with females being more likely to display this behavior). As presented in Table 3, gender was the primary predictor for drive for thinness (with females being more likely to display this behavior), followed by self-esteem, perfectionism and escape coping. As presented in Table 4, gender was the primary predictor for body dissatisfaction (with females being more likely to display this behavior), followed by self-esteem, stress, self-controlling and escape coping.

\section{Discussion}

The purpose of the present study was to measure various health behaviors in undergraduate students at a large Western university in order to better determine to what extent self-esteem manifests itself in these behaviors. We hypothesized that self-esteem would be the strongest predictor among others for disordered eating pathologies.

This study revealed self-esteem to be a predictor, although not the primary predictor as hypothesized. From these results one can infer that, in this sample, self-esteem plays an influential role in physical and psychological health. As reported, self-esteem was a secondary predictor for bulimia, drive for thinness and body dissatisfaction.

\section{Bulimia}

It appears that although self-esteem seems to play an important and influential role in levels and/or types of disordered eating, it is neither the most important nor the most influential. In our study, low self-esteem, working in concert with escape coping, stress and gender predicted bulimia. It is not surprising that escape coping predicted bulimia as Heatherton and Baumeister (1991) found that bulimia is often an escape response. This result supported the findings by Gilbert and Meyer (2005) who reported that self-esteem contributed, albeit indirectly, to an increase in bulimic attitudes. In addition, this result is further confirmed by Blaase and Elklit (2001) who found that those suffering from eating disorders were more likely than those who were not to suffer from low self-esteem, utilize poor coping tactics, and have higher stress levels. That being said, in terms of bulimia, further research should focus specifically on self-esteem, coping styles and stress as important risk factors in predicting bulimia. 


\section{Drive for thinness}

Furthermore, in regards to drive for thinness, our study found gender to be the primary predictor with self-esteem, perfectionism and escape coping all serving as additional predictors. These results seem to reflect an obvious trend in North American society that, especially for women, thin is ideal. Clearly then, it makes sense that this ideal would drive those women that are deemed perfectionists to cope by striving to become the thinnest they can. And, if these factors of maladaptive perfectionism and escape coping are buffered by a low self-esteem, it seems to only make sense that an intense drive for thinness would follow.

\section{Body dissatisfaction}

Much the same can be said for body dissatisfaction where again, gender was the most powerful predictor followed by self-esteem, stress, self-controlling and escape coping. It seems that body dissatisfaction and its predictors lay in the same vein as the drive for thinness.

\section{Limitations}

There were several limitations that may have affected the results reported in the present study. To begin with, future studies need to include a population beyond undergraduate college students enrolled in an introduction-level psychology course. Although this populous may be convenient to begin research, a more random sample of the general population would benefit research in this area. In addition, the survey administered was quite lengthy, there was not adequate time for every participant to finish and participants received the questions in the same order. All of these details may have lead to participant fatigue toward the end of the survey. In addition, as perfectionism is multidimensional, future researchers may wish to examine perfectionism with a scale that reflects this nature. All of these factors limit the generalizability of our findings. Because this study was cross-sectional in nature, we cannot make a causal link between disordered eating and self-esteem or any of our other factors. In addition, future researchers may wish to examine whether self-esteem mediates or moderates any of the relations between disordered eating and the other variables, especially in the long-term. Future work may also wish to examine the relations between these variables in clinical populations.

\section{Conclusion}

It is clear that each of the predictor variables (self-esteem, stress, coping style, perfectionism and gender) are inextricably intertwined in regards to how and to what extent they predict disordered eating. Self-esteem was a secondary predictor for each dependent variable studied. The implications of these findings are very telling. Selfesteem does indeed contribute to certain eating pathologies and thus, the status of one's health. Although further research may eliminate the hypothesis of self-esteem as the most powerful or primary predictor, we would conjecture that that same research will reveal self-esteem as a persistent, minimally secondary predictor that continues to influence psychological and physical health. It will be critical to include measures of self-esteem on further assessments of health in the general population. 


\section{References}

Abell, S. C., \& Richards, M. H. (1996). The relationship between body shape satisfaction and self-esteem: An investigation of gender and class differences. Journal of Youth and Adolescence, 25, 691-703.

Anderson, C. \& Bulik, C. (2004). Gender differences in compensatory behaviors, weight and shape salience, and drive for thinness. Eating Behaviors, 5, 1-11.

Bailer, U. F. \& Kaye, W. H. (2003). A review of neuropeptide and neuroendocrine dysregulation in anorexia and bulimia nervosa. Current Drugs Targeting CNS Neurological Disorders, 2, 53-9.

Blaase, H., \& Elklit, A. (2001). Psychological characteristics of women with eating disorders: Permanent or transient features? Scandinavian Journal of Psychology, 42, 467-478.

Bulik, C., Tozzi, F., Anderson, C., Mazzeo, S., Aggen, S., \& Sullivan, P. (2003). The relation between eating disorders and components of perfectionism. The American Journal of Psychiatry, 160, 366-368.

Button, E.J., Loan, P., Davies, J., \& Sonuga-Barke, E. J. (1997). Self-esteem, eating problems, and psychological well-being in a cohort of schoolgirls aged 15-16: a questionnaire and interview study. International Journal of Eating Disorders, 21, 39-47.

Eckerd, L. (2005). The relation of attachment style and perfectionism in women with eating disorder symptomatology. Dissertation Abstracts International: Section B: The Sciences \& Engineering, 65(12-B), 6647.

Espina, A., Ortego, M. A., Ochoa de Alda, I., Aleman, A., \& Juaniz, M. (2002). Body shape and eating disorders in a sample of students in the Basque country: A pilot study. Psychology in Spain, 6, 3-11.

Finstad, E. (2003). Identity and disordered eating in white, Hispanic, and American Indian adolescents. Dissertation Abstracts International: Section B: The Sciences \& Engineering, 64(2-B), 961.

Folkman, S., Lazarus, R. S., Dunkel-Schetter, C., DeLongis, A., \& Gruen, R. (1986). The dynamics of a stressful encounter: Cognitive appraisal, coping and encounter outcomes. Journal of Personality and Social Psychology, 50, 992-1003.

Furnham, A., Badmin, N., \& Sneade, I. (2002). Body image dissatisfaction: Gender differences in eating attitudes, self-esteem, and reasons for exercise. Journal of Psychology, 136, 581-596.

Garner, D. M., Olmstead, M. P., \& Polivy, J. (1983). Development and validation of a 
multidimensional eating disorder inventory for anorexia nervosa and bulimia.

International Journal of Eating Disorders, 2, 15-34.

Gilbert, N., \& Meyer, C. (2005). Fear of negative evaluation and the development of eating psychopathology: A longitudinal study among nonclinical women. International Journal of Eating Disorders, 37, 307-312.

Gleason, J. H., Alexander, A. M., \& Somers, C. L. (2000). Later adolescents’ reactions to three types of childhood teasing: Relations with self-esteem and body image.

Social Behavior \& Personality, 28, 472-480.

Granillo, T., Jones-Rodriguez, G. \& Carvajal, S. C. (2005). Prevalence of eating disorders in Latina adolescents: associations with substance use and other correlates. Journal of Adolescent Health, 36, 214-220.

Grilo, C., Masheb, R., Brody, M., Burke-Martindale, C., \& Rothschild, B. (2005). Binge eating and self-esteem predict body image dissatisfaction among obese men and women seeking bariatric surgery. International Journal of Eating Disorders, 37, 347-351.

Halmi, K., Sunday, S., Strober, M., Kaplan, A., Woodside, D., Fichter, M., Treasure, J., Berrettini, W., \& Hays, W. (2000). Perfectionism in anorexia nervosa: Variation by clinical subtype, obsessionality, and pathological eating behavior. The American Journal of Psychiatry, 157, 1799-1805.

Heatherton, T. F., \& Baumeister, R. F. (1991). Binge eating as escape from self-awareness. Psychological Bulletin, 110, 86-108.

Kiefer, I., Rathmanner, T., \& Kunze, M. (2005). Eating and dieting differences in men and women. Journal of Men's Health \& Gender, 2, 194-201.

Kohn, P. M., Lafreniere, K., \& Gurevhich, M. (1990). The inventory of college student’s recent life experiences: A decontaminated hassles scale for a special population. Journal of Behavioral Medicine, 13, 619-630.

Polivy, J., \& Herman, P. C. (2002). Causes of eating disorders. Annual Review of Psychology, 53, 187-213.

Pope H. G., Phillips K. A., \& Olivardia R. (2002). The Adonis complex: The secret crisis of male body obsession. New York: The Free Press.

Rector, N., \& Roger, D. (1997). The stress buffering effects on self-esteem. Personality and Individual Differences, 23, 799-808.

Rosenberg, M. (1989). Society and the adolescent self-image. Revised edition. Middletown, CT: Wesleyan University Press. 
Sassaroli, S., \& Ruggiero, G. (2005). The role of stress in the association between low self-esteem, perfectionism, and worry, and eating disorders. International Journal of Eating Disorders, 37, 135-141.

Shapiro, N. (1999). Self-esteem and the effect of feedback on laboratory and later eating in normal weight and overweight women. Dissertation Abstracts International: Section B: The Sciences \& Engineering, 59(9-B), 5111.

Suldo, S. M., \& Sandberg, D. A. (2000). Relationship between attachment styles and eating disorder symptomatology among college women. Journal of College Student Psychotherapy, 15, 5973.

Vohs, K. D., Bardone, A. M., Joiner, T. E., Jr., Abramson, L. Y., \& Heatherton, T. F. (1999). Perfectionism, perceived weight status, and self-esteem interact to predict bulimic symptoms: A model of bulimic symptom development. Journal of Abnormal Psychology, 4, 695-700.

Vredevelt, P., Newman, D., Beverly, H., \& Minirth, F. (1992). The thin disguise: Overcoming and understanding Anorexia and Bulimia. Nashville, TN: Thomas Nelson Inc.

Weltzin, T. E., Weisensel, N., Franczyk, D., Burnett, K., Klitz, C., \& Bean, P. (2005). Eating disorders in men: Update. Journal of Men's Health \& Gender, 2, 186-193. 

peer review, editing, corrections, structural formatting and other quality control mechanisms, may not be reflected in this document. Changes may have been made to this work since it was submitted for publication. The definitive version has been published in Personality and Individual Differences, 42, March 2007. DOI: 10.1016/j.paid.2006.10.026

Table 1

Gender Differences in All Variables - Means and (Standard Deviations)

\begin{tabular}{|c|c|c|c|}
\hline Variable & Men & Women & $t$ \\
\hline Drive for Thinness & $2.39(3.08)$ & $6.72(5.90$ & $9.36 * * *$ \\
\hline Bulimia & $1.18(2.28)$ & $2.46(4.18)$ & $3.85 * * *$ \\
\hline Body Dissatisfaction & $6.58(4.98)$ & $14.06(7.28)$ & $12.39 * * *$ \\
\hline Confrontive Coping & $7.36(3.13)$ & $7.33(3.15)$ & -.11 \\
\hline Distancing & $8.00(3.35)$ & 7.16 (3.09) & $-2.78 * *$ \\
\hline Self-controlling & $10.65(3.32)$ & $10.08(3.25)$ & -1.85 \\
\hline Social support & $7.58(3.05)$ & $8.48(3.48)$ & $2.89 * *$ \\
\hline Accepting Responsibility & $6.21(2.47)$ & $6.36(2.53)$ & .62 \\
\hline Escape Coping & $8.61(4.25)$ & $9.57(4.79)$ & $2.24 *$ \\
\hline Problem solving & $9.98(3.01)$ & $8.78(3.39)$ & $-3.92 * * *$ \\
\hline Positive reappraisal & $9.86(4.15)$ & $9.75(4.05)$ & -.28 \\
\hline Perfectionism & $26.84(5.62)$ & $26.62(5.73)$ & -.41 \\
\hline Stress & $1.07(.36)$ & $1.20(.39)$ & $3.66 * * *$ \\
\hline Self esteem & $.89(.61)$ & $1.10(.56)$ & $3.87 * * *$ \\
\hline
\end{tabular}

Note: $* * * p<.001, * * p<.01, * p<.05$ 

peer review, editing, corrections, structural formatting and other quality control mechanisms, may not be reflected in this document. Changes may

have been made to this work since it was submitted for publication. The definitive version has been published in Personality and Individual Differences, 42, March 2007. DOI: 10.1016/j.paid.2006.10.026

Table 2

Summary of Stepwise Regression Analysis for Variables Predicting Bulimia

Variable

Step 1

Escape Coping

.36

.03

$.46 * * *$

Step 2

Escape Coping

.28

.04

$.36 * * *$

Self-esteem

1.35

.28

$.22 * * *$

Step 3

Escape Coping

.24

.04

$.31^{* * *}$

Self-esteem

1.21

.28

$.20 * * *$

Stress

1.13

.43

$.12^{* *}$

Step 4

$\begin{array}{lccc}\text { Escape Coping } & .24 & .04 & .31^{* * *} \\ \text { Self-esteem } & 1.14 & .28 & .19^{* * *} \\ \text { Stress } & 1.02 & .43 & .11^{*} \\ \text { Gender } & -.66 & .29 & -.09^{*}\end{array}$

Note: $* * * p<.001, * * p<.01, * p<.05$ 

peer review, editing, corrections, structural formatting and other quality control mechanisms, may not be reflected in this document. Changes may

have been made to this work since it was submitted for publication. The definitive version has been published in Personality and Individual Differences, 42, March 2007. DOI: 10.1016/j.paid.2006.10.026

\section{Table 3}

Summary of Stepwise Regression Analysis for Variables Predicting Drive for Thinness

Variable

Step 1

Gender

$-4.33$

.46

$-.40 * * *$

Step 2
Gender
$-3.75$
.45
$-.35 * * *$
Self-esteem
2.72
.38
$.30 * * *$

Step 3

Gender

Self-esteem

2.02

.18

.04

.44

$-.37 * * *$

Perfectionism

Step 4
Gender
$-3.87$
.44
$-.36^{* * *}$
Self-esteem
1.54
.43
$.17^{* * *}$
Perfectionism
.15
.04
$.15^{* *}$
Escape Coping
.17
.05

Note: $* * * p<.001, * * p<.01$ 

peer review, editing, corrections, structural formatting and other quality control mechanisms, may not be reflected in this document. Changes may

have been made to this work since it was submitted for publication. The definitive version has been published in Personality and Individual Differences, 42, March 2007. DOI: 10.1016/j.paid.2006.10.026

\section{Table 4}

Summary of Stepwise Regression Analysis for Variables Predicting Body Dissatisfaction

Variable

Step 1

Gender

$-7.48$

.60

$-.50 * * *$

Step 2

Gender

$-6.76$

.59

$-.45^{* * *}$

Self-esteem

3.38

.49

$.27 * * *$

Step 3

Gender

$-6.60$

.59

$-.44 * * *$

Self-esteem

2.93

.52

$23 * * *$

Stress

2.00

.79

$.10 *$

Step 4

Gender

Self-esteem

Self-controlling

\section{Step 5}

Gender

Self-esteem

Stress

Self-controlling
$-6.41$

2.52
2.95

2.41

$-.18$

$-6.43$

.59

.52

.82

.09

$-.08 *$

$.13^{* *}$
$-.43^{* * *}$

$.24 * * *$

.59

$-.43^{* * *}$

.55

$.20 * * *$

1.81

.86

$.10 *$

$-.24$

.09

$-.11^{*}$ 
NOTICE: This is the author's version of a work accepted for publication by Elsevier. Changes resulting from the publishing process, including peer review, editing, corrections, structural formatting and other quality control mechanisms, may not be reflected in this document. Changes may have been made to this work since it was submitted for publication. The definitive version has been published in Personality and Individual Differences, 42, March 2007. DOI: 10.1016/j.paid.2006.10.026

\section{Escape Coping}

Note: $* * * p<.001, * * p<.01, * p<.05$
17

.08

$.11^{*}$ 